\title{
The Tribunal of Reason: Kant and the Juridical Nature of Pure Reason
}

\author{
Maria Chiara Pievatolo \\ The published version can be seen in: \\ Maria Chiara Pievatolo (1999) \\ The Tribunal of Reason: Kant and the Juridical Nature of Pure Reason \\ "Ratio Juris" 12 (3), 311-327. \\ doi:10.1111/1467-9337.00126 \\ http://www.blackwell-synergy.com/doi/abs/10.1111/blackwell \\ See the publisher's website for copyright terms and conditions.
}

\section{Introduction: contemplating or judging reason?}

This paper will propose an interpretation of Kant's thought based on an analysis of the wellknown Kantian metaphor of the "Tribunal of Reason". ${ }^{1}$ By so doing, it will be argued that the activity of reason is not foundational, but jurisdictional. The task of reason is not to form the foundation of our frameworks of theoretical and practical knowledge, but rather to form their legitimation. In addition, it will be argued that the non-foundational character of reason is consistent both with its ultimate autonomy and with its established proceedings. These are of a jurisidictional nature: the procedure of transcendental deduction. In other words, the nonfoundational character of reason does not imply that reason itself is indeterminate and vague (and therefore absolutely useless).

Kant believed that the critical task of reason was to single out and legitimate some a priori frameworks in our theoretical and practical knowledge. These frameworks constitute the syntax of knowledge. But do they enjoy unconditioned necessity?

If we answer that the a priori frameworks are unconditionally necessary, then Kant's reason, which discovers and legitimates them, plays a foundational role. In this case, Kant's reason would not be very different from idealistic reason, which plays a foundational role and is identical with reality. Indeed, it would presuppose an actual and necessary presence of these essential and indispensable frameworks. But this answer implies that Kant's critical work is altogether obsolete in the present day, because it considers the patterns of a particular scientific and ethical formulation as necessary and unavoidable. Therefore, if we question Newton's physics, which Kant appeals to, or some contents of his ethics, we cannot help imputing to Kant the same metaphysical dogmatism that he intended to avoid. ${ }^{2}$

However, Kant may be read in a different way. The reason that copes with the task of legitimating the validity of the a priori frameworks of our theoretical and practical knowledge does not prove they are unconditionally necessary, but only that they are conditionally necessary. In 
other words, legitimating them does not show that the a priori frameworks enjoy a necessary foundation, but only that they are possible under some conditions. The first answer supposes that the foundation of the a priori frameworks is a quaestio facti. The second answer, on the contrary, assumes that it is a quaestio iuris. In other words, reason does not ground the a priori frameworks, but legitimates their claims from reason's own point of view: that of a reflective and autonomous faculty. Indeed, only a reflective and autonomous faculty is able to question itself concerning the legitimation of our cognitive tools. If these tools were necessary in an unconditioned manner, there would be no need for us to choose, debate and justify them.

In its work of legitimating our a priori frameworks, reason attributes to them a conditioned necessity, similar to the legal one. It is not an absolute necessity, but a necessity relative to a particular perspective and particular proceedings. In recent years such an interpretation of Kant's thought has been developed by Lyotard, Kaulbach and Onora O'Neill. They all agree to attribute a jurisdictional and reflective character to pure reason ${ }^{3}$. And Kant himself uses the "Tribunal of Reason" metaphor. ${ }^{4}$

Two contending parties appeal to a court or a tribunal when they set up conflicting claims. But the parties agree to settle their quarrel in a legal manner, namely by following particular proceedings and a particular syntax. The very fact that there is a quarrel implies that neither claim enjoys an unconditioned necessity. And the one that follows from the decision of a court is only a conditioned necessity, namely an obligation valid only within a legal system. One may ask why Kant would prefer this weak necessity in his theory of knowledge?

Before answering this question, it is worth emphasising that the "Tribunal of Reason" metaphor is revolutionary. By it, reason is no longer a contemplating theoria, but a judging faculty. Contemplating reason characterised Western metaphysical tradition and was based on the priority of actuality. By contrast, Kant's judging reason is founded on the priority of possibility.

By the actuality of a thing, we mean that the thing itself is present, has come into effect, has fully developed. Conversely, by possibility we refer to the notion of being merely probable, at a time other than the present, or other than in the on-going experience.

Before Kant, the Western metaphysical tradition rested on the supremacy of actuality in two fundamental realms. The first was in the prime principles of knowledge, the second in the ontological framework of things. Positions of the Aristotelian scholastic mould can, in this regard, be considered paradigmatic. That is, the prime principles of knowledge and reality are actual in the sense that they are always and necessarily present as the basis of any form of knowledge, and it is impossible to disregard them. Furthermore, as far as the structure of things is concerned, the actual is logically stronger than the possible. The act is the condition of full realisation of a thing. And so it is possible to speak of virtual being, still in fieri, only when there is a presupposition of an actual being that is fully realised. ${ }^{5}$ 
This is the point of view of a contemplative reason. Our theoretical and practical principles of knowledge can be seen as well-founded when it is demonstrated that they are actual and always necessarily present in our knowledge. However, for a judging reason, this demonstration is not enough. In its perspective, we have to show that they are possible, namely that we can deduce and legitimate them within a fixed frame of reference.

Why does Kant use the "Tribunal of Reason" metaphor? Why is it no longer enough for him to establish that we de facto use certain cognitive tools? This paper suggests the following responses: Kant needs a judging reason because he realises that the rationalists and empiricists of his time present two kinds of actuality, which are in conflict with each other. The rationalists believe knowledge to be founded upon rational principles that are actual; always present and necessary. In opposition to this view, the empiricists believe that the evidence constituting the elements of knowledge is furnished by experience, in a manner likewise actual and unquestionable. Who is right? To answer this question, reason had to become a tribunal, which evaluates the legitimacy of conflicting claims.

A Tribunal cannot decree that one party is right simply because a certain behaviour is actual, in that it is the predominant habit in society. Thus Kant draws a distinction between the critique of reason, and an empiricist physiology of knowledge. (i.e. the explanation of how people know, which says nothing about the legitimacy of the framework of knowledge). Further, a tribunal is not a power that imposes itself, as does Machiavelli's new prince, but rather, a tribunal is legitimated as an organ of the Law.

Kant's critical reason is a derived, third organ that does not create, but gives an orientation. Yet, the deliberation of the Tribunal can occur only because the Tribunal puts forward, by itself, a law that is not included in the claims of the parties, but is issued by the Tribunal itself. The right ascertained by the Tribunal, however, is not something that is "discovered" in extant customs and precedents already formed. Thus the Tribunal of reason can be compared not so much to a common law court, as instead to a special constitutional tribunal.

Indeed, a common law court represents an institution that is also law-making at the same time. Hence it is not a mere bouche de la loi, and it acknowledges its own submission to an ideal of the law. This ideal is something other than the court's mere will, even though the only organ that discovers and issues this law is the court itself. Nevertheless, this type of tribunal, whether resting exclusively on a precedent, or acknowledging the role played by habit, presumes a state of legality already granted and unquestioned. The Kantian Tribunal of Reason, on the other hand, has to face a state of conflict and anarchy caused by a crisis of the traditional rules, and has to work out the very framework of its own legitimacy. Declaration of these new structures of legitimacy cannot boil down to the assumption of full power or the designation of a new prince, but must include the rules through which the claims of litigants can be settled. To achieve this, 
the constitution issued by the Tribunal should be procedural and open.

Any court enforcing a sham legitimacy to cover up de facto power would not be complying with its duty and would abase itself, becoming the prince's organ of propaganda. Thus among the essential characters of the Tribunal of Reason, autonomy and submission to a standard of legitimacy and legislation should be key features.

Kant's reason, if it is read according to the Tribunal metaphor, is a regulative reason, which inserts claims of knowledge - or more precisely, of different types of knowledge - into structures of legitimation. Since it is not creative, its task is not to criticize the reality of different pieces of knowledge, but rather their possibility. It should legitimate and systemize their structures, so that they may be unitary and reciprocally compatible. Any Tribunal which made decisions in an episodic and asystematic manner, influenced by the moods of judges, would not be a true Tribunal, but rather would be an arbitrary body. Likewise, a Tribunal making decisions based on other people's statements would be equally arbitrary. A judge is called upon to show both independence from different demands and submission to the Law: briefly, judges must be autonomous. This is what Kant says in What Is Orientation in Thinking?.

Freedom of thought also implies submission to the sole laws that reason applies to itself. The opposite is the maxim of unruly [gesetzlos] usage of reason. If reason refuses to submit to its self-imposed laws, it follows, quite naturally, that it will have to abide by the laws someone else has made. Without the existence of some law or other, nothing, not even the greatest absurdity will last for long. The inevitable upshot of this loose thinking [Gesetzlosigkeit] is explained here [Jacobi], as a liberation from the bounds imposed by reason. Because of such behaviour, freedom of thought will eventually be lost. Since misfortune is not to blame for this loss, but rather conceit itself, freedom of thought, in the true sense of the words, is seriously at stake. ${ }^{6}$

Reason itself, which seeks conditions and evaluates possibilities, is not inherently unconditioned and necessary. Reason can never operate without presupposing itself and its own autonomy. And any reason that was driven by something else would cease to be reason. It would become, to quote a Kantian simile, "no more than a roasting spit"7. But it should be emphasised that for Kant's reason, the need to presuppose itself, as a datum which cannot be systematised, as an insurmountable critical instance, is a kind of finiteness, rather than an absoluteness ${ }^{8}$. The critique of reason answers the question "What can I know?", "What ought I to do?", and "What may I hope?"9 This critique cannot answer such questions as "Why do I know?", or "Why should I be moral?". The bare fact of being in existence and of posing oneself questions does not imply any foundational activity. Kant's reason is subject, as it were, to Gödel's theorem: it can account for everything, but in it is contained an undecidable element, namely itself.

This weakness is also, at the same time, a strong point, because it is evidence of the nonmetaphysical character of Kant's reason. Reason is not a system given once and for all, but is a process. Thus, the form of legislation can be attributed to it, but it has no necessary content. Kant 
speaks of the Beruf jedes Menschen, selbst zu denken ${ }^{10}$ in his What Is Enlightenment?. Reason has the character of a vocation, almost as a religious calling. It is a strictly personal calling that is impossible to impose or define from the outside, because it is something that can be evaluated only by the person concerned. In the place of necessity, Kant poses autonomy of thought and the framework of its conditions and possibilities.

It is worth pointing out that Kant's reason is autonomous and non-foundational, but cannot be reduced to an indeterminate principle that is compatible with any paradigm. Indeed it uses a welldetermined and accurate procedure - transcendental deduction - which is the direct result of the autonomy and legislative power peculiar to reason itself. Therefore, this paper will now analyse some transcendental deductions in Kant's work, to show that a non-foundational reason cannot be reduced to a loose principle, so that, as it were, all cats are equally grey in the night. ${ }^{11}$

\section{Deduction in the work of Kant}

The interpretation of Kantian thought that is being presented is anti-idealistic. The idealists interpreted Kant's reason as an actual principle, potentially logical and ontological. But herein, we presume instead that reason is a reflective rationality of the juridical type; a process, in itself finite, of an organization of possibilities and limitations. In fact, one of the most important subjects, albeit of a more strictly juridical origin, of Kant's thought is, indeed, deduction.

The term deduction, in Kant's language, is derived from jurisprudence and indicates the demonstration of the legitimacy of determinate claims, as distinct from proof of matters of fact ${ }^{12}$. The most agonizing and famous deduction is the transcendental deduction contained in the Critique of Pure Reason. The object of this deduction is the legitimation of the cognitive use of categories of understanding. The question that makes deduction necessary is, in brief, as follows: some instruments of knowledge - called by Kant categories ${ }^{13}$ - have been recognised as not deriving from experience, but from our understanding. So then we may wonder whether it is legitimate or not to use them in the cognitive sphere.

This query is not groundless, but may be raised only because two circumstances of fact are considered as given: on the one hand, sensible intuitions; on the other, categories of understanding. It could be maintained that the crisis of univocality of evidence revealed by the opposition between empiricism and rationalism is re-proposed through this duality. Sensible experience cannot be deduced - in a logical sense - from categories, nor, on the contrary, can be categories from sensible experience. Hume had been absolutely clear about this ${ }^{14}$. Thus a legitimation, called transcendental deduction, is needed to show how a unitary cognition can be furnished even though two types of reciprocally independent evidence are present. On the side of sensibility we have a virtually infinite manifoldness; on the side of understanding, we find a finite number of categories. 
But will the latter be of any use?

The task of legitimation presupposes, at least as focus imaginarius, an unity of cognition. Without this presupposition, conflict between rationalistic and empiricistic evidence would not even exist. Thus, if the problem of legitimacy in using categories is to be discussed, a subject or substratum must be presupposed as ready to recognize both types of conflicting evidence as its own. Should this recognition fail, the conflict could not even occur. Kant calls this substratum I think, for the very reason that it is not an "unconscious " stage on which representations are held. Rather, it is something active, which operates and recognises the representations as its own.

The conflict between sensible and intellectual evidence can be proposed only if both can function in concert with each other. Further, the conflict can only be proposed if the virtually infinite manifoldness offered by sensible evidence is made intelligible by categories. This must be done in such a fashion that this evidence may even, if need be, oppose the results, whose acquisition and classification by understanding have so far been taken for granted.

It should be stressed that transcendental deduction develops through a series of hypothetical conditions. So, if the conflict is to be settled, we have to presuppose a virtual unity of cognition and subjectiveness in which this cognition occurs and whose unifying functions must be categories. In conclusion, the I think is not an ultimate, actual, unavoidable type of evidence but rather a possibility introduced by an "if". It is not the foundation of reality and rationality, but only a logicalcognitive condition. This condition should be able to accompany cognition according to categories, if we wish that such a cognition be unitary and therefore subject to discussion and criticism. The hypothetical condition of the I think, though, determines neither the type of categories nor the type of representations. It only requires that they be recognizable, unifiable and systematizeable, besides being, as far as categories are concerned, unifying and systematizing.

Hegel's reading of this deduction was instead a metaphysical one - as if Kant had intended to deduce, in a logical sense, the table of categories from the necessary reality of the I think. Hegel therefore judged the Kantian undertaking to be ruinous. He maintained that there was no connection between the ego, as unity of self-consciousness, and the categories which were to be the unifying functions of its cognition. Instead, he maintained that the connection remained a merely empirical one. The Hegelian critique would be pertinent if this transcendental deduction were metaphysical, if it intended to deduce categories from the actuality of a self-consciousness which legitimates itself because it is a source, at the same time, of reality and cognition. But in relation to the instruments of thought, Kant does not pose the metaphysical question of their "reality", namely, of their connection with the structure of things, but rather the "juridical" question of their validity and their use (Chiodi 1961, 10-13).

Whereas idealists harkened back to a concept of foundation as actuality, necessary reality, unconditionedness; Kant, dismissing metaphysics, conceived of foundation as condition and limit. 
By reducing Kant to a metaphysicist, the idealists treated him as though he had transferred the function of logical-ontological foundation, in the traditional sense, to the subject. And as if Kant subsequently failed in the attempt to determine the categorical structure of the subject, taking the latter's necessary and unconditioned productivity as a starting point. On closer inspection, however, it becomes clear that from Kant's point of view such a demonstration would be worthless. Even if one succeeded in demonstrating that categories are the necessary structure of the subject, inasmuch as the latter is cognisant and self-conscious, their cognitive use would by no means be legitimated (Chiodi 1961, 21-59). Who can say whether these alleged necessary frameworks are not the anatomy of dream? Who can assume that through them we may know?

To Kant's mind, the question to be posed is different, namely: on what conditions and within what limits can we use a given function in a legitimate manner? To put it another way: an ultimate and ever-present - because unavoidable - foundation of cognition and reality is, from a Kantian point of view, something with very little significance. Indeed, if this ultimate and unavoidable foundation is actually operating as such, then every mode of cognition lies within it and cannot escape. What then is the use of engaging ourselves in consideration of such a matter? If it is an unavoidable foundation, we cannot in any case do without it. Thus It would seem more fruitful to be concerned with possible and avoidable foundations; it is these that require demonstration and legitimation, for the very reason that we can do without them.

The fundamental thesis of this reading of Kant is that the traditional notion of foundation accounts for possibilities by tracing them back to the unique and unconditioned order of absolute reality. But Kant traces necessity back to the varied and problematic order of conditions of possibility and the several spheres of validity opened up by them (Chiodi 1961,13 ff). Thus, several deductions can be singled out in Kantian thought, according to the type of concept and sphere of validity to which they refer. For instance, Kant draws a distinction between laws of nature and laws of liberty, and endeavours to show that explanatory concepts of theoretical cognition do not consistently suit the realms of law and ethics. In general, the issue of deduction arises because an automatic and inevitable necessity does not occur. Deductive reason would be meaningless in the realm of the necessary, and the actual, but it functions, like a Tribunal, within the sphere of the possible. The unconditioned - Kant maintains - cannot be thought of without contradiction. First, let us clarify what is meant by transcendental deduction in general.

Hegel, as has already been mentioned, interpreted Kantian deduction as if its goal was the determination of categories in their totality and necessity and in their relationship with selfconsciousness $^{15}$. However, Kant raises the problem of deduction after, and not before, expounding his categories. Deduction does not endeavour to justify the relationship between categories and unity of self-consciousness, but rather the relationship between any type of a priori determination and the possibility of the corresponding object. In the case of transcendental deduction of 
categories, it is a question of the relationship between these and the corresponding object. The fact that the need for deduction arises reveals that the relationship is not absolute, but is only possible. Hence its conditions of validity, which are subject to being contravened, must be shown (Chiodi 1961, 33-38).

Since it pertains to the instruments of our cognition, transcendentality of deduction is one of its analytical characters. A thing cannot be legitimated empirically, on the basis of a physiology of cognition. Similarly, a Tribunal could not declare a type of behaviour legitimate merely because of its diffusion in society. In short, deduction is the main characteristic distinguishing the critical philosophy of Kant from either empiricist or rationalist approaches. It is impossible to legitimate an a priori form empirically. And similarly, the attempt to extract an object from logic proves fruitless.

Transcendental deduction rests on the distinction between quaestio juris and quaestio facti; the right and scope of the claims of our pure concepts are not contained analytically in the fact. Thus Kant, although still expressing himself as if the formal order of thought was natural, brings its conditions into question, from a non-naturalistic point of view (Chiodi 1961, 38-44). The fact that the concepts to be legitimated do exist and are in use does not automatically entail the legitimacy and validity of their use. The statement that categories are inherent in the physiology of our cognitive faculties provides no help at all when trying to clarify whether and to what extent resorting to them for knowledge can be sanctioned.

The concepts of philosophy express a field of claims which should have their foundation not in exhibition of their necessity, but rather in the display of their legitimate possibility. Kant draws a clear distinction, in his Critique of Judgement, between Feld or field (the sphere of claims of a concept, independently of the possibility of its foundation), Boden or territory (that part of field where such a possibility exists), and Gebiet or dominion (that part of the territory where validity is real, i.e. wherein it genuinely refers to possible things) ${ }^{16}$. On the same territory, different dominions can co-exist, according to the conditions of validity that form the legitimate use of a concept. For instance, both intellectual legislation of nature and rational legislation of liberty exert their dominion over experience, according to whether the prospect of explanation or that of moral and juridical law is adopted (Chiodi 1961, 50-52).

To illustrate the significance of transcendental deduction, let us briefly consider the the pure concepts of understanding, i.e. categories. The issue regarding this deduction is basically the vexing question of the relationship between our representation and the object (Chiodi 1961, 72). How can we rest assured that conformity exists between these two terms? To this question three traditional metaphysical solutions had been given; but they were dismissed altogether by Kant, as early as February 21,1772 , in a letter to Marcus Herz: ${ }^{17}$

- relationship of an active subject with a passive object (intellectus archetypi), on whose intuition the facts themselves are founded; 
- relationship of an active object with a passive subject (intellectus ectypi) whose representations are completely determined by the influence of their object;.

- operation of an active God upon a subject and an object, both passive (Malebranche's occasionalism).

The first two solutions are dismissed by Kant, as they presuppose an absolute and unconditioned action, whose inexistence is confirmed by the mere presence of two conflicting interpretations of intuition. An absolute and unconditioned action, immediately laden with conceptual content, could not even be brought into question. The third solution, the occasionalistic one, is discarded because it entails a vicious circle, since the deux ex machina that takes care of harmonizing cognisant with cognised is introduced by the same cognitive faculty, which needs to be legitimated.

These three traditional solutions have in common the explanation of the relationship between representation and the object with a scheme of the cause and effect type. What is assumed as prius, whether it be God, or the cognisant subject, or the object offered by experience, is treated as a foundation. This foundation has the characters of unconditionedness, because it is the prime cause of presentiality and necessity inasmuch as it cannot be otherwise than what it is. Even for Kant, foundation and necessity coincide, but necessity and unconditionedness do not. One can speak of foundation only in relation to types of legitimacy, which are to be determined in each case, according to particular conditions of validity (Chiodi 1961, 81).

To put it another way, traditional metaphysics justified, or better, explained, the conformity between representation and the object, by ascertaining the presence of a logical prius, of a foundation which functioned as a prime cause. Thus, two mistakes were made. In the first place, metaphysics treated itself as an external object; it reasoned as if on the one hand it knew the object independently of the object's representation, and on the other, as if it knew the representation itself. Secondly, metaphysicst took for granted that the category of cause could be appropriately used to define the relationship between cognition and representation.

Kant's reason is, instead, a reflective reason that submits its own possibilities and limits to criticism. And since it is reflective, it is not at all capable of treating itself as if it could see itself from the outside, as an object of experience. Thus, the problem for reason is not that of the impossible exhibition of an absolute foundation, but rather that of a criticism which can clearly establish how and when its own categories are to be used. In this case, for instance, how and when to use the categories of cause. Therefore, the problem of deducing categories is divided into the following points (Chiodi, 1961, 88):

1. there exist a priori concepts of understanding;

2. the ascertainment of this fact poses the problem of their legitimacy and conditions of use;

3. any demand for legitimacy is a claim for necessity; 
4. any claim for necessity requires deduction for determinaton of its conditions;

5. if a plan existed in which necessity and unconditionedness coincided, no deduction would be possible. But since we can speak of necessity only when determined conditions are concerned, i.e. from given points of view and given prospects, the metaphysical universe shatters into a myriad of images of the world. The tribunal of reason judges on the basis of a few fundamental principles that imply its own autonomy and desire for unity and systematicity, but which rests on a plurality of potential codes.

In the second edition of Critique of Pure Reason (1787), Kant formulates the problem of deducing categories as a problem of logical/transcendental, not psychological possibility of a general unification. The foundation of unification is represented by unity insofar as it is a possibility: "Das: Ich denke muß alle meine Vorstellungen begleiten können." (It must be possible for the 'I think' to accompany all my representatio $)^{18}$

In order for the manifoldness of sensibility to be the object of a cognition, a unification is required. This, in turn, demands a unity that functions as a substratum. This unity, on the other hand, cannot be furnished a parte objecti: indeed, it is impossible to demonstrate that what we experience is in itself unitary and consistent, mainly because today's experience could be contradicted by tomorrow's experience. So this unity is to be sought a parte subjecti, in the relationship between the self-consciousness of the I think and all the other representations.

Each manifoldness of intuition has a necessary relationship with the I think, in the same subject where this manifoldness is met. Such a relationship is expressed by the muß begleiten Können.

Schopenhauer (1938, I: 535) criticized this statement by saying that with one hand it took back what it gave with the other. It was, to his mind, a modally ambiguous statement, because it was both apodictic (i.e. unconditionally asserted to be necessary: "mu $\beta$ ") and problematic (expressing a mere possibility: "können"). It seems, then, that Kant's thesis is subject to two different interpretations, depending on whether the "muß " or "können" is stressed.

In the first case, it would mean that the unity of sensible knowledge resting on categories is assured by the fact that the I think necessarily accompanies each representation of mine. In the second case, it would mean that the unity of knowledge resting on categories is assured by the fact that the I think can accompany each representation of mine.

The first interpretation, in the style of traditional metaphysics, founds the unity of knowledge upon the unconditioned necessity of the presence of self-consciousness. If we accept this interpretation, the task of deduction will be superfluous. There is no need for us to legitimate the use of categories if the I think is always necessarily present, properly structured, together with each representation of ours. In the second case, instead, it would follow that unity of knowledge occurs according to categories only when it is possible that the I think accompanies each representation of mine. 
Surprisingly, Kant uses the curious wording "must be able". The unity of self-consciousness, that is, of the substratum within which validity of categories can be discussed and legitimated, is not an absolute but a conditioned necessity. In order for the conflict between sceptics and dogmatists to take place, i.e. for the very problem of legitimation to be posed, this unity must be possible. Let us clarify this statement as follows: if we wish to reflect on our knowledge, its self-conscious unity must be possible. So, conditionally, to obtain unity of self-consciousness, it must be possible that the I think accompanies each representation of mine. In summary, "must" expresses a necessity connected with the possibility of unity of self-consciousness and does not express an absolute necessity (Chiodi 1961, 232-68). On what condition, let us now ask, is it possible for the I think to accompany each representation of mine?

It is, of course, not enough to have representations: in this case consciousness could be reduced to an unconscious theatre where perceptions follow one another. But it could not be maintained that these representations are unified by the fact that all of them parade, one after another, on this stage. There must be the conscious activity of a spectator to unify them. There must be a subject who can succeed in identifying these representations as his own, in giving them a sense and consistency by utilizing, for this purpose, the functions of categories. In order to achieve unification, it must therefore be possible for the I think to accompany each representation. The I think, though, is not an empirical, perceiving subject. For clearly, in this case, nothing could assure the unity of knowledge, if by knowledge we mean an inter-subjective heritage. It is a possibility that must be presupposed as valid in order that an objective unity of knowledge can be obtained. This unity, in short, is not in the object, but rather in a possible subject.

The need, as has been seen, is for transcendental deduction to be derived from a crisis of the univocity and indisputability of evidence, inasmuch as rationalism and empiricism presented two opposing types of evidence, (one intellectual and the other sensible). In contrast, the critical Kantian requirement was expressed by a finite reason, self-given, incapable of denying evidence (intuitions) and of reconstructing from itself and by itself a totality that would be identified with reality. Thus, transcendental deduction of categories occurs over categories that are not just concepts of the object in general, but which are concepts of intuition in general (Chiodi 1961, 251-57).

To re-state this more clearly, let us resort again to the judicial metaphor. The judge, although independent and subject only to the ideal of legislation and systematicity, must take heed only of the claims of the parties who have appointed him. Clearly, he is not a legislator/demiurge who builds the world ex novo; instead, he is compelled to abide only by what the litigants have submitted to him. This is also true in the case of a special constitutional court endeavouring to find a remedy for anarchy by settling the dispute among conflicting claims. In short, and in the non-metaphorical dimension, Newton's physics and Euclidean geometry (with their concepts of time and space), are not the sole forms of cognition possible in their respective realms. The judge who deals with them 
attempts to establish the legitimacy and limits of their claims, should they appear as parties before him. However, he by no means rules out that other parties, belonging to the same sphere, may bring their case before the law. Think for instance of Einsteinian physics and non-Euclidean geometries, which are capable of adducing different and perhaps better reasons.

If categories, and in general any a priori concepts, are detached from the field in which, in a conditioned manner, they have validity, and from the corresponding conditions of validity, an absolute field is not reached. It is simply the case that all meaning and significance are removed from their dominion, just as a tribunal legislating in vacuo would be quite meaningless. Hence the important role played by schematism, which through figurative synthesis organises the framework of categories, in the form of temporal structures.

In conclusion, the critique of reason operates according to a juridical logic in two fundamental theses: First, at no level is reality, as mere presentiality, capable of being valued as foundation. (Chiodi 1961, 267). That is, fact does not constitute a right; and second, foundation occurs only through its inclusion in structures of possibilities. In the same way, the legal system is a system of possibilities. Deduction of any claim whatsoever does not occur, in a jurisdictional sense, by virtue of exhibition of the fact, but rather through its inclusion in a hypothetical framework; that of possibilities.

\section{Practical reason as a scope of validity.}

In the preface to the 1787 edition of the Critique of Pure Reason, Kant addressed the problem of the moral sphere, by manifesting the need for a transcendental deduction of the conditions and limits on its validity: "The dogmatism of metaphysics is the real source of the scepticism that is opposed to morality". ${ }^{19}$ In this case too, Kant is confronted with a crisis of evidence, whether it be rationalistic evidence (the ideal of perfection), or empiricist evidence (the doctrines of moral sentiment). Withn the moral sphere, the most remarkable clue to this crisis of evidence is represented by the manner in which Kant treated the ideal of happiness. ${ }^{20}$

Traditional ethics saw happiness - to wit, full realisation of human potentialities - as its pivotal concept. Happiness was the end that oriented and defined moral behaviour as well as the political order. Kantian ethics, on the other hand, moved away from the tradition, saying that happiness cannot be the foundation of universal and obligatory rules because it does not have a univocal, determinate and evident content. Clearly, in this form, the idea of happiness is an ideal of totality, i.e. as much prosperity as possible. But the content of this ideal is empirical and consequently neither evident, nor determinable once and for all. Rather, as regards its ends, happiness depends on the opinions of the people concerned, while the means to achieve the ends depend on experience, which is inherently particular and contingent. ${ }^{21}$ 
In the second place, were everybody to share the same concept of happiness, we could not rest assured that such a concept would give rise to rules capable of possessing inter-subjective value. Desiring the same thing does not mean agreement upon the rules of behaviour to be followed. There is a quip by Francis I that Kant quotes as an example: "What my brother Charles desires (Milan), that I desire too." 22 If law and morality are defined as a body of inter-subjective rules, such rules cannot be determined teleologically, even in the exceptional event of an agreement over the ends to pursue.

Likewise, the evidence of happiness as the foundation of morality rested on the necessary and unconditioned presence of a metaphysical framework: human nature. The crisis of evidence, manifested by the conflict between rationalism and empiricism, makes this path impassable. Further, ethics founded on fact can, at best, furnish a phenomenology of morality. But it cannot offer any argument in favour of the obligation of a certain behaviour without falling into contradiction. Indeed, if human nature truly acted in an effective and necessary fashion, it would be utterly superfluous to enunciate the obligation to follow one's own nature, since the naturalistic foundation would be operative, always and without possibility of exception.

Similarly, practical reason, a fortiori, does not rest on the ascertation of the presence of an unconditioned and necessary actuality. It is, rather, a sphere of validity that has as its threshold certain conditions of possibility. Therefore the central issue of practical reason is how, and under what limits, are a priori principles possible, as practical and objective laws?

...the moral law, although it gives no view, yet gives us a fact absolutely inexplicable from any data of the sensible world and the whole compass of the theoretical use of reason, a fact that points to a pure world of the understanding, nay, even defines it positively and enables us to know something of it, i.e. a law [...] There are therefore two very distinct problems: how, on the one side, reason can cognise objects a priori, and how on the other side it can be an immediate determining principle of the will ${ }^{23}$.

Practical reason and theoretical reason differ in their relationship with evidence, with the issue of the immediate matter of fact. As regards knowledge, the presence of evidence, of intuition, is not incompatible with legislation by reason, provided that some possible structures capable of accounting for it can be worked out and legitimated. But in the case of morality, things are quite different. A certain evidence is not to be explained by including it into a structure of possibilities, but a structure of rules mist be planned that do not have to account for the evidence. These are, instead, entrusted with the task of sketching a possible world, entirely to be realised. This framework of rules, set free as it is from experience, should respect solely those characters by which reason is given to itself. It should thus be formal, universal and also be such as not to contravene its own condition.

Clearly, a legislation of reason is possible if and only if it formulates rules in such a way as to respect the possibilities of the will - and consequently the moral subjectivity - of any rational being. 
In other words, these rules must be such that they can be desired as universal laws by and for every possible rational being. Moral subjectivity is the acknowledgement of the possibility of making free and conscious choices. For instance, a rational being who lies to someone thereby implicitly denies the latter's moral subjectivity, for the very reason that the person lied to is deprived of the possibility of making a thoroughly conscious choice.

We would expect a transcendental deduction of the framework of moral law, but Kant offers no such thing. Instead, he asserts that moral law is a Faktum der Vernunft ${ }^{24}$, and that it cannot be a matter of experience, because the existence of the moral law cannot be proven empirically. Indeed no example of moral behaviour can properly be exhibited, for the simple reason that any moral behaviour does not exemplify by its phenomenality, but rather insofar as it is judged by us in a certain perspective. Besides, a behaviour can be morally imputable only on the presupposition that it is free. But the structures of empirical knowledge belong to the explanatory type, and consequently we have no opportunity to know freedom ${ }^{25}$.

This can be re-stated, for the sake of clarity, as follows: we are not thinking of the determinism of physical science of Kant's day, but simply of any explanation whatsoever of a historical event. An historian endeavouring to give an account of a human behaviour relates it to a set of background events that act as its conditioning. If he confined himself to maintaining that such behaviour was free, and consequently original and unconditioned in comparison with the past, he would by no means compose a historical narration, but merely a loose list of disconnected, nonsensical events.

Thus, the practical sphere is one of validity introduced by the question "What ought I to do?" which presupposes freedom as its condition. But is it not the case that the circumstance that moral law is a matter of reason lets back in through the window what Kant chased out of the door, namely, foundation as presentiality, factuality, unconditioned necessity? After all, Kant begins his discourse by saying there is a fact, a duty, for any rational being to behave within the limits of the legislation yielded by the autonomy of reason. We might ask ourselves: how can we rest assured that such a "fact" possesses an objective value? ${ }^{26}$

A possible solution to this problem is founded upon the thesis that Kant's practical interests were substantially the following: First, to remove the moral world from the type of conditioning of transcendental deduction of pure concepts of understanding, and thus from the logic of explanation; second, to remove the moral world from the deceptive unconditionedness of metaphysical foundation; and third, to found the moral world upon its specific conditions of validity (Chiodi 1961, 273-79).

In this perspective, the moral world is not unconditioned in absolute terms, but solely in connection with the world of knowledge. And this would be the way of being of a particular type of conditioning. In other words, it is not unconditioned in the manner of the old metaphysics: simply, it is theoretically inexplicable. This interpretative thesis should be substantiated by the fact that 
practical reason does not at all explain the totality of the real, merely confining itself to what a rational being must do.

Reason itself, after all, is not a presence that is necessary in an unconditioned manner, but rather a vocation. Therefore, reason is something which remains beyond any possibility of deduction, either in a juridical or a speculative sense of the word.

The fact that critical reason is self-given is its impassable limit. Reason can include everything into structures of legitimation, except its own freedom and demand for explanation. Furthermore, none of these structures of legitimation are, in themselves, absolutely necessary and actual. Rather, their validity, being introduced through conditions of possibility, is merely hypothetical. As far as morality is concerned, the rational factualness of the law may be explained as follows: if we wish to justify our behaviour within the limits of a rational legislation - whenever such a legislation does not coincide with the material sharing in ends and ideals of happiness - then we must at this stage presuppose moral law to be a horizon apodictically given, from a theoretical point of view. In general, the limit of reason is not something external to it, but neither is it an arbitrarily traced boundary. It is, rather, reason's mere being in existence and its proposition of itself as a vocation, which can account for everything, except itself. ${ }^{27}$

\section{Abstract}

This paper will propose an interpretation of Kant's thought based on an analysis of the well-known Kantian metaphor of the "Tribunal of Reason." By so doing, it will be demonstrated that the activity of reason is not foundational, but jurisdictional. The task of reason is not to form the foundation of our frameworks of theoretical and practical knowledge, but rather to form their legitimation - not as a necessity, but rather as a possibility. In addition, it will be argued that the non-foundational character of reason is consistent both with its ultimate autonomy and with its established proceedings, i.e. the procedure of transcendental deduction. In other words, the non-foundational character of reason does not imply that reason itself is indeterminate and vague (and therefore absolutely useless).

Maria Chiara Pievatolo Dipartimento di Scienze della politica, Facoltà di Scienze politiche - Università di Pisa

Via Serafini, 3

I- 56100 Pisa ITALY

pievatolo@dsp.unipi.it 


\section{References}

Aristotle, 1924, Aristotle's Metaphysics / A revised text with introduction and commentary by W. D. Ross, Oxford, Oxford Clarendon Press.

Cassirer, Ernst, 1921 Zur Einstein'schen Relätivitatstheorie, Berlin, B. Cassirer.

Chiodi, Pietro,0 1961. La deduzione nell'opera di Kant, Torino, Taylor.

Forschner, Maximilian, 1988. Moralität und Glückseligkeit in Kants Reflexionen, in "Zeitschrift für philosophische Forschung", 44/3: 351-70.

Hegel, Georg Wilhelm Friedrich, 1986, Encyclopädie der philosophischen Wissenschaften in Grundrisse. Frankfurt a. M.. Suhrkamp.

Kant, Immanuel 1968, Kants Werke, Akademie Textausgabe, Berlin, De Gruyter.

Kaulbach, Friedrich, 1982. Studien zur späten Rechtsphilosophie Kants und ihrer tranzendentalen Methode, Würzburg, Könighausen \& Neumann.

Kaulbach, Friedrich, 1985. Die Kopernikanische Wendung von der Objektwahreit zur Sinnwahrheit bei Kant, in Wahrheit und Begrundung, ed. by. V. Gerhardt und N. Herold, Würzburg, Könighausen \& Neumann.

Kutschmann, Wilhelm., 1988, Erfinder und Entdecker oder Richter der Natur? Die kantsche RichterMetapher und die Selbstlosigkeit der modernen Naturwissenschaften, in Zeitschrift für philosophische Forschung, 43/1: 32-57.

Landucci, Sergio, 1990. Sulla meta-etica diKant nella "Critica della ragion pratica", in Rivista di filosofia, 8/1 1: 57-82.

Lyotard, Jean.-François, 1986 L'enthousiasme. La critique kantienne de I'histoire, Paris, Galilée.

Nancy, Jean-Luc, 1983, L'impératif catégorique, Paris, Flammarion, 35-60,

O'Neill, Onora, 1989. Construction of Reason. Exploration of Kant's Practical Philosophy, Cambridge, Cambridge U.P.

O'Neill, Onora, 1992a. Vindicating Reason, in A Cambridge Companion to Kant, ed. by P. Guyer, Cambridge, Cambridge U.P., 280-305.

O'Neill, Onora, 1992b. Reason and Politics in the Kantian Enterprise in Essays on Kant's Political Philosophy, ed. by H. Williams, Cardiff, University of Wales Press, 5079.

Pera, Marcello, 1982, Hume, Kant e l'induzione, Bologna, il Mulino.

Reichenbach, Hans, 1920, Relativismus und Erkenntnis Apriori, Berlin, Springer.

Schopenhauer, Arthur, 1938, Sämtliche Werke. Leipzig, Brockhaus; Bd. I: Die Welt als Wille und Vorstellung. 
1. Kant uses the metaphor of the Tribunal of Reason in several of his works. A clear explanation of its meaning can be found in the Preface to the second edition of Critique of Pure Reason: "Reason, holding in one hand its principles, according to which alone concordant appearances can be admitted as equivalent to laws, and in the other hand the experiment which it has devised in conformity with these principles, must approach nature in order to be taught by it. It must not, however, do so in the character of a pupil who listens to everything that the teacher chooses to say, but of an appointed judge who compels the witnesses to answer questions which he has himself formulated." (Kritik der reinen Vernunft, B XIII)

2. Suffice it to think, for instance, of the debate which opposed Reichenbach (1920), together with all Neo/Positivists and logical Empiricists, against the Neo-Kantian Cassirer (1921). The argument at issue was the tenability of Kantian gnoseology, insofar as it is built upon traditional arithmetics, Euclidean geometry and classical Galilean-Newtonian physics. Following the recent development of pure mathematics (set theory, mathematical logic) of non-Euclidean geometries and Einsteinian relativity, Reichenbach acknowledged, in a Kantian fashion, the requirement of a priori principles and elements in knowledge, but denied that these a priori were given and determined once and for all. Indeed, the contemporary post-modern reading is closer to Reichenbach's than to Cassirer's.

3. Outstanding examples of this are J.F. Lyotard (1986) in France, F. Kaulbach $(1982,1985)$ in Germany and O. O'Neil (1989, 1992a, 1992b) in England.

4. For other perspectives on this subject see J.L. Nancy (1983, 35-60) and also W. Kutschmann (1988).

5. Aristotle, Metaphysics, IX, 8, 1049 b $10 \mathrm{ff}$.

6. I. Kant, Was heißt sich Im Denken orientieren?, AK VIII, $131 \mathrm{ff}$.

7.I. Kant, Kritik del praktischen Vernunft, AK 173-174. Kant, of course, used this simile to separate his own concept of freedom from that of Leibniz. Since a spiritual automaton is determined by representations rather than by material causes, it is in no way freer than a material automaton. Its freedom is, in fact, the freedom of a roasting spit.

8. Consider the famous passage of the Critique of Pure Reason in which unconditioned necessity is called "the veritable abyss" for human reason. Now, unconditioned necessity is inherent in what is an ultimate unavoidable foundation, from which it is impossible to deviate; but one cannot help thinking: "What is it that founds the foundation?". This is also true for anyone wishing to read Kantian reason in an idealistic fashion. The fact that reason cannot do without selfpresupposition in its own autonomy is not, properly speaking, a foundation, but rather a chasm. The fact that reason cannot get out of itself does not entail its identity with the totality of reality (Kritik der reinen Vernunft, B 641-A 613)

9. I. Kant. Logik, AK 25-26

10. I. Kant, Beantwortung der Frage: Was ist Aufklärung? AK 483.

11. An argument of this sort was suggested by an Italian philosopher, Pietro Chiodi (1961), who was known mainly for his studies on Heidegger and existentialism. Chiodi's theses did not only anticipate contemporary debate by several years, but also tackled these difficulties successfully. Chiodi's reading of Kant will be duly borne in mind throughout the course of this paper. In fact, the goal is to show the linkage between the non-foudational activity of reason and a determined procedure, i.e. transcendental deduction. And this linkage may be viewed as a direct by-product of Chiodi's interpretation of Kant.

12 I. Kant, Kritik der reinen Vernunft B 116/B 117-A 84.

13 Among them, causality deserves to be mentioned as a pivotal function of scientific reasoning .

${ }^{14}$ I See, on this subject, Pera (1982).

15. G.W.F. Hegel, Enc., I, § 42.

16. Chiodi (1961, 49-52), cfr. I. Kant, Kritik der Urteilskraft, AK XV-XVI.

17. AK X 129-135. Chiodi, (1961,. 69-75).

18. Kant, Kritik der reinen Vernunft, B 131; Chiodi, (1961, 232- 268).

${ }^{19}$. Kant, Kritik der reinen Vernunft, B XXX.

20. For example, see Forschner (1988).

21. This topic is treated in Grundlegung zur Metaphysik der Sitten.

22. I. Kant, Kritik der praktischen Vernunft, AK 50 (It. version p. 35).

23. Ibidem, AK 74 and 77.

24. Ibidem, AK 55-56.

25. Ibidem, AK 80-87.

26. See, on the subject, S. Landucci (1990) who maintains that Kant, within the moral scope, is in the final analysis an intuitionist, because in his thought, the structure of morality effectively rests on fact, upon a matter of reason, hence upon something that reason assumes as immediately certain and incontestable

27. The present text is a revision of a paper presented at the Seminar Nuove prospettive interpretative della razionalità pratica, held by Ms Barbara Henry - to whom my special thanks are due - at the Scuola Superiore Sant'Anna of Pisa, during the Academic Year 1993-94. 